\title{
VALSE VERWAGTINGE AAN DIE KAAK GESTEL: DIE FUNKSIE VAN DIE HEILSTRADISIES IN JEREMIA 7:1-15
}

\author{
W Vosloo en M D Terblanche
}

\begin{abstract}
FALSE EXPECTATIONS EXPOSED: THE FUNCTION OF TRADITIONS IN JEREMIAH 7:1-15

In Jeremiah 7:1-15 various traditions are employed in different ways. The expectations based on the Zion Tradition, namely that Jerusalem is inviolable because of Jahweh's presence, are exposed to be false. This is done with reference to the Sinai Tradition, accentuating that Jahweh's saving acts are not determined by his presence in the temple, but by Juda's loyalty to the prescriptions of Sinai. Furthermore, the Conquest Tradition is used to describe the extent of the judgment in store for Juda, namely the loss of the land.
\end{abstract}

\section{Inleidend}

Jeremia 7:1-15 is 'n sleutelperikoop in die boek Jeremia. Jeremia 7:18:3, waarvan Jeremia 7:1-15 'n prominente deel vorm, is die eerste groot prosastuk in die boek ná die inleidende eerste hoofstuk. Jeremia 7:1-15, wat ook as die tempelpreek van Jeremia bekend staan, is nie alleen by die tempel" gelewer nie, maar raak ook die posisie van die tempel as sodanig. Aangesien die tempel volgens Jeremia 7:4 deur talle Judeërs as waarborg vir Jahwe se toekomstige verlening van heil beskou is, is die funksie van die verskillende Israelitiese heilstradisies in Jeremia 7:1-15 van besondere betekenis vir die bepaling van die boodskap van die gedeelte. Vandaar hierdie ondersoek na die funksie van die heilstradisies in die bepaalde perikoop.

\section{Afgrensing van die perikoop}

Soos bo vermeld, vorm Jeremia 7:1-15 deel van die groter prosastuk, Jeremia 7:1-8:3. Benewens die feit dat 7:1 volgens die Massoretiese teks die opskrif tot hoofstukke 7-10 vorm ${ }^{2}$, dien dit saam met vers 2 as inleiding tot Jeremia 7:3-15. Tematies is daar 'n duidelike breuk tussen verse 15 en 16. In laasgenoemde vers ontvang die profeet die opdrag om nie vir die volk wat afgodsdiens bedryf te bid nie, terwyl vers 15 die gevolge van die valse vertroue in die tempel uitwys. Verder is daar ' $n$ wisseling in aangesprokenes: In 7:1-15 praat Jahwe met die volk van Juda, terwyl Hy in 7:16-18:3 die profeet aanspreek, ingelei met die formule w'th. 


\section{Struktuur}

Benewens die inleidende verse 1 en 2, word Jeremia 7:1-15 gewoonlik in 'n paranetiese gedeelte ( $v$ 3-7) en ' $n$ veroordelende gedeelte ( $v$ 8-15) verdeel. ${ }^{3)}$ Omrede die boodskappersformule in vers 3 op die hele tempelpreek betrekking het, kan hierdie indeling nie aanvaar word nie. Dit is veelseggend dat die oproep tot inkeer wat in vers 3 aangetref word, breër in verse 5-7 uitgewerk word. Waar die kondisionele sin in vers 3 slegs ' $n$ enkele protasis bevat, word 'n hele reeks in verse 5 en 6 gevind. ${ }^{4)}$ Opmerklik is ook die gebruik van die konstruksie bestaande uit die werkwoord škn, die nota accusativi 't en die frase bmmqwm $h z z h$ in sowel vers 3 as vers 7 . hnnh in vers 8 lei 'n nuwe onderafdeling in.

Tussen vers 4 en verse $8-15$ bestaan ook 'n duidelike verband, alhoewel laasgenoemde in twee onderafdelings uiteenval, naamlik verse 8-11 en 12-15. Die partikel $k j$ in vers 12 is emfaties ${ }^{5)}$ en lei ' $n$ nuwe onderafdeling in. Die voorkoms van die formule $n$ ' $m$ jhwh aan die einde van vers 11 bevestig hierdie argument. In verse 8-11 word die gruwels wat Juda bedryf vanwee die valse verwagtinge wat hulle aan die tempel koppel, geskets, terwyl die verwoesting van Silo as waarskuwing in verse 12-15 voorgehou word. 'n Verdere argument wat aangevoer kan word, is die feit dat die frase bthjm $\mathrm{km} \%$ / dbrj hššq in vers 8 bykans identies aan vers $4 \mathrm{a}$ is.

In die lig van bogemelde moet verse 3-4 as 'n samevatting van verse 5-15 beskou word. Jeremia 7:3-15 kan dus soos volg ingedeel word: 'n samevatting van die boodskap van die tempelpreek (v 3-4), 'n oproep tot bekering ( $\vee 5-7)$, ' $n$ berisping $(v 8-11)$ en 'n dreigement ( $v 12$ 15).

\section{Die Sionstradisie}

Die frase hjkl jhwh hjkl jhwh hjkl jhwh hmmh in 7:4 is 'n aanhaling van 'n stelling wat uitdrukking gee aan die volk se vertroue in die onskendbaarheid van die tempel. Die drievoudige herhaling van hjkl jhwh dui op die belangrikheid wat aan die tempel van Jahwe as waarborg van toekomstige heil geheg is. Die verwagtinge wat met die Sionstradisie geassosieer is, kom hier aan die orde. Die tempel was immers die fokuspunt van die Sionstradisie waarin die verkiesing van Sion as woning van Jahwe beklemtoon is. Mettertyd het die idee ontstaan dat Sion weens die teenwoordigheid van Jahwe aldaar onaantasbaar was.

Volgens Jeremia 26:1 het die profeet aan die begin van die regering van koning Jojakim opdrag van Jahwe ontvang om in die tempel die woord van Jahwe te bring aan die Judeërs wat daar kom aanbid. Moontlik moes die profeet dit tydens die loofhuttefees in September/Oktober 609 doen. ${ }^{6}$ Die skielike dood van koning Josia by Megiddo het tot gevolg gehad dat Juda binne die invloedsfeer van Egipte beland 
het en 'n einde gebring het aan alle pogings om die grootheid van die Dawidiese era te herstel. Daarteenoor het die aansien van die tempel gestyg. Die farao Nego het dit immers onaangeraak gelaat, terwyl die volk van die land belas is om die tribuut wat deur Nego geëis is, te voorsien ( $v g l 2$ Kon. 23:35). Dié gebeure is waarskynlik gesien as 'n bevestiging van die geloof in die onaantasbaarheid van die tempel. Daarbenewens is die aansien van die tempel reeds deur Josia se hervorming en die daaropvolgende Deuteronomistiese beweging verhoog.

Die teenwoordigheid van Jahwe in die tempelkompleks is as ' $n$ waarborg vir die toekomstige verlossing gesien. Die term $\mathrm{hmmh}$ aan die einde van 7:4 het waarskynlik op die tempelkompleks betrekking." In die Ou Testament verwys die term $h j k /$ nie slegs na die hoofvertrek van die tempel nie, maar dit word ook met betrekking tot die hele tempelkompleks gebruik, byvoorbeeld in Haggai 2:15. Volgens Rose ${ }^{8)}$ was $h j k l$ die vroegste terminus technicus vir die tempel in Jerusalem. Die voorstel dat $h m m h$ in Jeremia 7:4 as 'n afkorting van bmmqwm hzzh beskou moet word, ${ }^{9)}$ hang saam met die siening dat $m q w m$ in 7:1-15 na die tempel verwys. Dit is nie noodwendig die geval nie, soos later aangetoon sal word.

Die vergelyking wat in 7:12-15 tussen Silo en die tempel in Jerusalem getrek word, bevestig dat die verwagtings wat met die Sionstradisie geassosieer is, in 7:1-15 ter sprake kom. Die uitgangspunt in verse $12-15$ is die siening dat Sion Silo opgevolg het as plek wat Jahwe tot heiligdom verkies het. Hy het Silo verwerp. Daarvan was die ballingskap van die noordelike stamme (7:15) 'n bewys. Net so sal Hy Sion verwerp met die gevolg dat Jerusalem verwoes en Juda in ballingskap gevoer sal word.

Tot redelik onlangs is die verwoesting van Silo waarna in Jeremia 7:12 en 14 verwys word, in verband gebring met die gebeure ná die slag van Afek, in ongeveer $1050 \mathrm{vC}$, toe die Filistyne Israel verslaan het. Buhl en Holm-Nielsen ${ }^{101}$ het egter tydens 'n herwaardering van die opgrawings wat by Silo gedoen is, tot die gevolgtrekking gekom dat die stad eers in die agste eeu vC vernietig is. Die gevolg is dat persone soos Pearce "1) en Schley ${ }^{12)}$ van mening is dat Jeremia 7:12 en 14 verwys na ' $n$ verwoesting van Silo in die tyd toe die Noordryk in ballingskap gegaan het. Die feit dat die einde van die Noordryk in 7:15 as waarskuwing aan Juda voorgehou word, bevestig skynbaar hierdie standpunt. Tog veronderstel die argument in Jeremia 7:12, 14 en 15 ook die lotgevalle van die ark in die elfde eeu $v C .{ }^{13)}$ Die argument is immers dat Jahwe nie onlosmaaklik gebonde is aan 'n bepaalde heiligdom nie. Waarskynlik is die verwoesting van Silo in die 8ste eeu voor Christus beoordeel as die eindpunt van die proses wat met die verlies van die ark in die 11 de eeu voor Christus begin het. 


\section{Die Sinaïtradisie}

Die frase hgnb rșh wn'p wat in Jeremia 7:9 voorkom, herinner aan die agste, sesde en sewende gebooie in die Dekaloog. Alhoewel die frase hgnb rșh wn'p wat die vorm van die werkwoord betref nader verwant is aan Hosea 4:2 as aan enige van die twee weergawes van die Dekaloog in Eksodus 20 en Deuteronomium 5, kan die verband met die Dekaloog nie negeer word nie. Die Dekaloog vorm 'n integrale onderdeel van die Sinaitradisie wat volgens Von $\operatorname{Rad}^{14)}$ gebaseer is op die oortuiging dat Jahwe by Sinaï bindende bepalings aan sy volk geopenbaar het op grond waarvan 'n verhouding met Hom moontlik gemaak is. Dit is dus duidelik dat dit die Sinaïtradisie is wat in Jeremia 7:9 benut word.

Die werkwoord $j d$ ' word dikwels gebruik om die verhouding tussen Israel en Jahwe te beskryf, byvoorbeeld in Jeremia 31:34. Die frase I'$j d^{\prime} \mathrm{tm}$ in Jeremia 7:9 sou egter nie as 'n sinspeling op hierdie verhouding, en daarmee op die Sinaï-gebeure, gesien kan word nie (teenoor Thompson) ${ }^{15)}$ Die frase dui hier, soos wat dit ook in 16:13 die geval is, op iets wat onbekend is. In 7:9 verwys dit na gode wat tevore onbekend was.

\section{Die landbesettingstradisie}

Indien Juda in ballingskap sou gaan, soos wat in Jeremia 7:15 in die vooruitsig gestel word, beteken dit dat hulle die land wat Jahwe aan hulle vaders gegee het, sou verloor. Dit is dus nie verbasend dat die landbesettingstradisie ook ' $n$ belangrike rol in Jeremia 7:1-15 speel nie. Die herhaalde voorkoms van die term mqwm is in hierdie verband veral van belang. Alhoewel mqwm in vers 12 betrekking het op die heiligdom wat te vore in Silo bestaan het, verwys dit in vers 14 na Jerusalem as pars pro toto van die land wat Israel met die intog ontvang het. ${ }^{16)}$ In 7:3 en 7 hang die betekenis van mqwm ten nouste saam met die keuse wat ten opsigte van die vorm van die werkwoord škn gemaak word. In die Massoretiese teks word dit as 'n pi'el-vorm gevokaliseer. Jahwe sal sy volk in die mqwm, dit wil sê in Jerusalem en daarmee in die land laat woon. Die Vulgaat, aan die ander kant, suggereer dat die werkwoord as qal gevokaliseer moet word. Jahwe sal onder sy volk woon. Dan verwys mqwm na die tempel. In vers 7 word die frase bmmqwm hzzh gevolg deur die term b'rs. Die vraag is of hulle in apposisie staan, of anders of $b$ 'rs nie ' $n$ veel omvattender term as $m q w m$ is wat na die stad of die tempel verwys nie? $\mathrm{Na}$ aanleiding van die gebruik in 7:14 lyk dit asof $m q w m$ in verse 3 en 7 na Jerusalem as deel van die land verwys en dat die Massoretiese vokalisasie gevolg moet word. Dit stem ooreen met die gebruik van bmmqwm hzzh in vers 6 waar die verwysing na die onderdrukking van die vreemdeling, wees en weduwee en die vergieting van bloed die identifikasie van bmmqwm hzzh met die tempel uitsluit. 
Benewens die feit dat daar in die perikoop sterk gesinspeel word op Jahwe se heilsdaad toe Hy die land Kanaän aan sy volk gegee het, word die verblyf in die land afhanklik gemaak van 'n lewenswyse wat in ooreenstemming is met die eise van Jahwe (vers 3 ). Thiel ${ }^{17)}$ is van mening dat die verblyf in die land nie in die oorspronklike tempelrede ter sprake gekom het nie, maar dat die sogenoemde Deuteronomistiese redaksie dit te berde gebring het omdat sy hoorders met die vraag geworstel het of hulle ongestoord in die verwoeste land sou kon bly. Volgens McKane ${ }^{(8)}$ hoort slegs verse 4, 9, 10; 11, 12 en 14 tot die oorspronklike kern. Daarop is uitgebrei deur die toepassing van die tema van die besit/verlies van die land.

Hierdie tema kom elders in die boek Jeremia herhaaldelik in gedeeltes voor wat tot dieselfde tipe prosa behoort as dié wat in Jeremia 7:1-15 aangetref word. In hierdie verband kan gewys word op Jeremia $24: 10 ; 25: 5 ; 30: 3$ en $35: 15$. Die tema van die besit van die land is egter nie vreemd aan die poëtiese gedeeltes in die boek Jeremia nie. In 2:413, 20-22 en 3:19-25 word dit gebruik om die irrasionaliteit van die volk se gedrag in Kanaän te beklemtoon. Ten spyte van al die seëninge wat die volk geniet het as resultaat van die gawe van die beloofde land aan hulle, was hulle ongehoorsaam aan Jahwe.$^{19)}$ In die poëtiese 17:1-4 het die tema van die verlies van die land dieselfde funksie as in 25:1-14 en $35: 1-19$, naamlik om die omvang van die komende oordeel te beskryf. Juda sal die land wat Jahwe aan hulle vaders gegee het, verloor. ${ }^{20)}$ In 7:1-15 het die landbesettingstradisie 'n soortgelyke funksie, alhoewel dit in verse 3, 5-7 in 'n kernteks gebruik word waarin daar nog ruimte vir bekering gelaat word.

Die skynbare teenstelling tussen hierdie verse wat nog ruimte vir bekering laat, en verse 8-15 wat 'n oënskynlik onafwendbare oordeel in die vooruitsig stel, skryf Thiel ${ }^{21}$ aan die sogenoemde Deuteronomistiese redaksie toe. Die redaksie sou volgens hom Jeremia se tempelrede verander het in ' $n$ preek met die hoofkenmerk die stel van die alternatiewe van heil en onheil. Ten spyte van die aanloklikheid van hierdie hipotese kan Thiel geen verduideliking gee vir die feit dat 'n perikoop soos 11:1-14 wat net soos 7:1-15 tot die preekagtige prosa behoort, geen ruimte vir bekering laat nie. Gevolglik moet daar ook nie te veel gemaak word van die feit dat 'n voorwaardelike element in 7:3, 5-7 gevind word, terwyl 'n skynbaar onherroeplike strafaankondiging in verse 8-15 gevind word nie. Verder moet selfs diegene wat beweer dat die tema van die besit/verlies van die land nie tot die oorspronklike tempelrede behoort het nie, toegee dat dit implisiet in ' $n$ aankondiging van 'n onafwendbare oordeel aan die orde móés kom. 


\section{Die funksie van die onderskeie heilstradisies}

Daar bestaan 'n breë konsensus dat Jeremia 7:1-15 nie teen die tempelaanbidding as sodanig gerig is nie. ${ }^{22)}$ 'n Saak word soms daarvoor uitgemaak dat die idee dat Jahwe in die tempel woon, in die perikoop bestry word. In hierdie verband moet op die gebruik van die formule bjt 'šr nqr' šmj ' $w$ in Jeremia 7:10, 11 en 14 gewys word. Dit word gesien as 'n aanduiding van die voorkoms van die šem-teologie wat dit ten doel gehad het om die gedagte dat Jahwe onverbreeklik met die tempel verbonde was, teë te werk. Die nqr' šm '/-formule druk gewoonlik besit uit, byvoorbeeld in 2 Samuel 12:28; Jesaja 4:1 en Psalm 49:12. Mettinger ${ }^{231}$ is egter van mening dat dit ook gebruik word om die teenwoordigheid van Jahwe aan te dui. Dit is volgens hom die rede waarom die formule in 1 Konings 8:43 aangewend word. Verbasend genoeg gebruik Mettinger Jeremia 14:9 waar Jahwe se teenwoordigheid onder sy volk beklemtoon word, om sy argument te staaf. In hierdie vers waarin die volk na alle waarskynlikheid aangehaal word, word die stelling gemaak: " $U$ is tog in ons midde, Jahwe, en $u$ Naam is oor ons uitgeroep. Verlaat ons nie!" Jeremia 14:9 gee eerder uitdrukking aan die tempelteologie wat deur die šem-teologie bestry is as wat dit gebruik kan word om die voorkoms van die šem-teologie in Jeremia 7:1-15 te staaf. $\mathrm{Na}$ aanleiding van Jeremia 14:9 sou eerder afgelei kon word dat die nqr' šm ' 1 -formule ook in Jeremia 7:1-15 besit uitdruk. Die gebruik van die formule b'jr 'šr ngr'-šmj lih in Jeremia 25:29 met betrekking tot die stad Jerusalem is veelseggend. Aangesien die tempel nie direk ter sprake kom nie, sou aanvaar kon word dat die betrokke formule ook hier besit uitdruk.

Die uitdrukking 'šr škkntj šmj šm in 7:12 hou inderdaad verband met die šem-teologie. Alhoewel die werkwoord bhr, wat in verwante uitdrukkings in Deuteronomium 12:11; 14:23; 16:2, 6 en $26: 2$ voorkom, afwesig is in Jeremia 7:12, is die uitdrukking 'šr škkntj šmj šm eerder Deuteronomies as Deuteronomisties. ${ }^{24)}$ Die uitdrukking het egter op die heiligdom in Silo betrekking en nie op die tempel in Jerusalem nie. $\mathrm{Na}$ aanleiding van bostaande, kan die standpunt dat die sogenoemde Deuteronomistiese redaksie Jeremia se tempelrede in 7:1-15 in die lig van die šem-teologie nie gebruik om die opvatting dat Jahwe in die tempel teenwoordig was, te bestry nie. Dieselfde is waar van die weergawe van die tempelrede in 26:1-24, wat volgens Thie $\left.\right|^{25)}$ ook aan die sogenoemde Deuteronomistiese redaksie onderworpe was.

Soos reeds vermeld, word Juda in Jeremia 7:8-15 gewaarsku dat Sion 'n lot soortgelyk aan dié wat Silo getref het, te wagte kan wees. In die geloof dat Sion danksy die teenwoordigheid van Jahwe onskendbaar was, het Juda volgens verse 8-10 van die tempel 'n plek gemaak waar persone waarvan die lewens gekenmerk is deur ongehoorsaamheid aan Jahwe se eis bymekaar gekom het om hulleself te verseker 
dat hulle veilig met hulle aktiwiteite kan voortgaan. Om die onhoudbaarheid van hierdie toestand aan te toon, word in vers 9 na die Sinaitradisie teruggegryp. Juda was besig om die gebooie wat God aan die volk by Sinai gegee het, te minag. Hulle kon dus Jahwe se oordeel verwag. Gevolglik word die Sinaitradisie hier gebruik om die verwagtinge dat Sion, en daarmee Jerusalem, outomaties verseker was van Jahwe se beskerming, te bestry.

Jeremia 7:10 en 11 toon 'n verdere aspek ten opsigte van die gebruik van die Sinaitradisie. Vers 10 lê klem op die feit dat diegene wat die gruwels doen, dit selfs waag om voor Jahwe se aangesig in die tempel te verskyn. Alhoewel die term qdwš hier nie gebruik word nie, is dit duidelik dat die heiligheid van die tempel deur die samekoms van die diewe, moordenaars, egbrekers, persone wat meineed gepleeg het, en afgodsdienaars aangetas word. In vers 11 word beklemtoon dat Jahwe die ontheiliging van die tempel raaksien. Die partikel $g m$ het hier 'n versterkende betekenis. ${ }^{26)}$ Die Sinaitradisie word dus benut om die ontheiliging van die tempel, wat die fokuspunt van die Sionstradisie was, uit te wys. Jahwe se teenwoordigheid in die tempel word egter geensins betwis nie. Die voorwaardelikheid van Jahwe se verbintenis met die tempel word egter duidelik uitgewys. Indien Juda nie die verpligtinge wat Jahwe by Sinai op sy volk gelê het, nakom nie, sou Jahwe sy teenwoordigheid in Sion beëindig. Die Sinaitradisie word gebruik om die erns van Juda se oortredinge uit te wys, maar verskaf ook die grond vir die oordeelsaankondiging in 7:12-15.

Alhoewel verwysings na die intogtradisie veral in vers 3 en die daarmee samehangende verse 5-7 voorkom, word 'n pertinente verwysing daarna in vers 14 gevind in die frase w/mmqwm 'šr-ntttj lkm wl'bwtjkm. Soos reeds genoem, word in 7:14 waarskynlik na 'n verwoesting van Silo in die tyd toe die Noordryk in ballingskap gegaan het, verwys. Soos wat die inwoners van die Noordryk in ballingskap weggevoer is uit die land wat Jahwe aan hulle vaders gegee het, sal Juda ook hulle land verloor. Dit is duidelik dat die landbesettingstradisie aangewend word om die omvang van Jahwe se oordeel te beskryf. Vir Israel was die intog ' $n$ besondere heilsdaad van Jahwe. Die bewoning van die land was egter afhanklik van die uitvoering van die voorskrifte wat Jahwe by Sinai aan die volk gegee het. By gebrek hieraan sou Jahwe dit wat hulle met die landbesetting ontvang het, hulle ontneem.

\section{Samevattend}

Die teenwoordigheid van Jahwe in Sion word nie in Jeremia 7:1-15 betwis nie; die valse verwagtinge dat Sion weens die teenwoordigheid van Jahwe onskendbaar was, word wel betwis. Juda se ontrouheid aan 
die bepalings wat God by Sinai gegee het, sou egter aanleiding gee tot die beëindiging van Jahwe se teenwoordigheid in Sion. Die Sinaitradisie word dus gebruik om die verwagtinge wat met die Sionstradisie geassosieer is, in perspektief te plaas. Hierbenewens word die landbesettingstradisie benut om die omvang van Jahwe se oordeel oor Juda te beskryf. Die oordeel wat die ontroue Judeërs hulleself op die hals gehaal het deur aan die valse verwagtings ten opsigte van Sion se onskendbaarheid vas te hou, sou tot gevolg hê dat hulle die beloofde land wat hulle vaders van Jahwe ontvang het, sou verloor.

\section{NOTAS}

1. Die Septuaginta-lesing van Jeremia 7:1-2 is beperk tot die frase $s m$ ' $w d b r$ jhwh $k l$ jhwdh. E Tov, "Some aspects of the textual and literary history of the book of Jeremiah", in: P-M Bogaert, Le livre de Jérémie. Le prohéte et son milieu. Les oracles et leur transmission. Leuven 1981, 149, is van mening dat die Septuagintateks van die boek Jeremia 'n vroeëre redaksie as dié wat in die Massoretiese teks oorgelewer is, weerspieël.

2. PK D Neumann, Hört das Wort Jahwäs. Ein Betrag zur Komposition alttestamentlicher Schriften, Hamburg 1975,287.

3. H Lörcher, "Das Verhältnis der Prosareden zu den Erzählungen im Jeremiabuch." Ongepubliseerde inaugurale dissertasie wat by die Eberhard-Karls Universiteit, Tübingen ingedien is, 1974,61 .

4. Die 'I van '/ t\$pkw is grammatikaal onaanvaarbaar en moet na /' verander word selfs al is daar nie stawende teksgetuienis nie. Rudolph (1968:50) beskou die frase $w d m n q j$ ' $l-t s \breve{p} p k w$ as ' $n$ sekondêre invoeging na aanleiding van Jeremia 22:3. 10.

5. W L Holladay, Jeremiah 1. A commentary on the book of Jeremiah, chapters 1-25. Philadelphia, 1986,247.

6. W L Holladay, "The years of Jeremiah's preaching." Interp vol 37(1983), 149.

7. J Bright, Jeremiah, Garden City ${ }^{2} 1965,55$.

8. M Rose, Der Ausschliesslichkeitsanspruch Jahwes. Deuteronomistische Schultheologie und die Volkströmmigkeit in der späten Königzeit, Stuttgart 1975,216.

9. R P Carroll, Jeremiah, London 1986,207.

10. M-L Buhl,en S Holm-Nielsen, Shiloh. The Danish excavations at Tell Sailun, Palestine, in 1926, 1929, 1932 and 1963. The pre-hellinistic remains, Copenhagen 1969,62 .

11. R A Pearce, "Shiloh and Jer VII 12, 14 \& 15." VT vol 23(1973), 108.

12. D G Schley, Shiloh. A Biblical city in tradition and history, Sheffield 1989,181 .

13. Pearce, a $w, V T$ vol 23(1973)), 107-108.

14. G von Rad, Theologie des Alten Testaments, Band I. Sechste Auflage. München $1969,188$.

15 J A Thompson, The book of Jeremiah, Grand Rapids 1980,280.

16. W Thiel, Die deuteronomistiche Redaktion von Jeremia 1-25. Neukirchen-Vluyn $1973,109$.

17. W Thiel, a $w, 109$.

18. W McKane, A critical and'exegetical commentary on Jeremiah, Edinburgh '1986, 164-165.

19. M D Terblanche, "The function of the traditions in Jeremiah 1-45". Ongepubliseerde DD-proefskrif ingelewer by die Universiteit van Pretoria 1988,44-48.

20. M D Terblanche, $a w, 160$. 
21. W Thiel, a $w, 116$.

22. R P Carrol, a $w, 209$.

23. T N D Mettinger, The dethronement of Sabaoth. Studies in the Shem and Kabod theologies, Lund 1982,64.

24. D G Schley, a $w, 176$.

25. W Thiel, Die deuteronomistiche Redaktion von Jeremia 26-45. Mit einer Gesamtbeurteilung der deuteronomistischen Redaktion des Buches Jeremia. NeukirchenVluyn 1981,3-4.

26. A Van Selms, Jeremia, Deel I. Nijkerk 1980,130. 